\title{
Resectable gastric signet ring cell carcinoma: clinicopathological characteristics and survival outcomes
}

Ines Zemni ${ }^{*}$, Houyem Mansouri ${ }^{1}$, Ines Ben Safta ${ }^{1}$, Mohamed Ali Ayadi ${ }^{1}$, Tarek Ben Dhiab ${ }^{1}$, Riadh Chargui ${ }^{1}$, Khaled Rahal ${ }^{1}$

${ }^{1}$ Department of surgical oncology, Salah Azaiez Institute, Faculty of Medicine of Tunis, University Tunis el Manar. Tunisia.

\section{To Cite}

Zemni I, Mansouri H, Ben Safta I, Ayadi MA, Ben Dhiab T, Chargui R, Rahal K. Resectable gastric signet ring cell carcinoma: clinicopathological characteristics and survival outcomes. J Gastric Surg 2020; 2(3): 71-78

\section{Publication history}

Received: August 4, 2020

Accepted: August 30, 2020

Article in press: August 31, 2020

Published online: September 1, 2020

\section{*Correspondence to}

Dr. Ines Zemni

Department of surgical oncology

Salah Azaiez Institute

Faculty of Medicine of Tunis

University Tunis el Manar

Avenue 9 Avril Bab Saadoun

1006 Tunis, Tunisia

Telephone: +21671563980

ines.zemni@yahoo.fr

\begin{abstract}
Background:

Gastric signet ring cell carcinoma (SRCC) appears to have clinical features and survival rates particularly different from other histological types. The aim of this study was to investigate clinicopathological features and survival outcomes of SRCC and to compare them with non-signet ring cell carcinoma (NSRCC).

Methods:

We retrospectively studied 145 patients with non-metastatic gastric carcinoma who underwent gastrectomy in our institute from 2005 to 2015. Among them, 36 patients (9.4\%) with SRCC were compared to 109 patients $(90.6 \%)$ with NSRCC.
\end{abstract}

Results:

Patients with SRCC presented at a younger age $(\mathrm{p}=0.001)$ with more advanced stage III-IV disease $(\mathrm{p}=0.005)$ and advanced $\mathrm{N}$ stages with a higher rate of $\mathrm{pN} 3(\mathrm{p}=0.0001)$, a higher number of invaded lymph nodes $(\mathrm{p}=0.002)$ and a higher rate of patients with a lymph node ratio exceeding $25 \%(63.9 \%$ vs $36.7, \mathrm{p}=0.004)$. After a median follow up of 35.30 months, there was no significant difference in the 5 years overall (OS) survival between SRCC and NSRCC ((36.7\% vs $45.7 \%, p=0.206)$. However, the 5 years progressive free survival (PFS) was significantly decreased in case of SRCC $(38.7 \%$ vs $50.9 \%, \mathrm{p}=0.038)$ with a higher rate of metastasis in $(52.9 \%$ vs $29.5 \%, \mathrm{p}=0.013)$ and peritoneal recurrence $(35.3 \%$ vs $9.5 \%, \mathrm{p}<0.0001)$. The main prognostic factors of PFS and OS in SRCC were tumoral stenosis, hypoprotidemia, tumor size, depth of invasion $(\mathrm{p}=0.001)$, perineural and lymphovascular invasion, the UICC stage and complete surgical resection.

Conclusion:

Gastric SRCC have a particular clinicopathological behavior compared to NSRCC suggesting its more aggressive character.

Keywords:

gastric cancer, signet ring cell carcinoma, pathology, prognosis. 


\section{Background}

Gastric signet ring cell carcinoma (SRCC) is defined as an adenocarcinoma composed of isolated or small groups of malignant cells with abundant intracytoplasmic mucinas predominant component (more than $50 \%$ of the tumor).[1, 2]According to Lauren's classification, SRCC and gastric linitis, are part of the diffuse type. [3] Another Japanese classification separates gastric adenocarcinoma into two groups: differentiated and undifferentiated.[4]"Differentiated" cancers include well-differentiated, moderately differentiated and papillary adenocarcinoma. "Undifferentiated" cancers consist of poorly differentiated adenocarcinoma and SRCC.[5] SRCC appears to have clinical features and survival rates particularly different from other histological types according to the stage at diagnosis. The aim of this study was to investigate clinicopathological features and survival outcomes of SRCC and to compare them with non-signet ring cell carcinoma (NSRCC).

\section{Methods}

The medical records of 145 patients who underwent curative or palliative gastrectomy for non-metastatic gastric adenocarcinoma from January 2005 to December 2015 were retrospectively reviewed. From all, 36 patients had histologically proven gastric SRCC. Exclusion criteria were as follows: metastatic disease, other synchronous tumoral location, unknown surgery status, unknown vital status; incomplete pathological data, and less than $50 \%$ of signet ring cells. Demographic data (Sex, age), clinical presentation, tumor size, tumor location, histopathological variables, (lymph node ratio (LNR), microscopic invasions (venous, perineural or lymphovascular invasion), TNM stage, type of surgery and associated resection were recorded. Lymph node metastasis ( $\mathrm{N}$ stage) and depth of tumor invasion ( $\mathrm{T}$ stage) were classified according to the 8th edition of the American Joint Committee on Cancer/International Union Against Cancer (AJCC/UICC) TNM staging system.

Statistical analysis

Continuous data were summarized using descriptive statistics (mean, standard deviation (SD), median, minimum, and maximum values). Categorical data were summarized using frequency and percentages. Clinicopathological differences between NSRCC and SRCC were compared with the Chi-square test for categorical variables. Overall survival (OS) was calculated as the time from surgery to death of any cause or the last follow-up date. Progressive-free survival (PFS) was measured from the time of surgery to initial tumor relapse (local or distant recurrence) or the initial tumor progression in patients with incomplete resection. Survival curves were generated using the Kaplan-Meier (KM) method and then compared with the log-rank test. Differences were considered to be statistically significant when $p<0.05$. All statistical analyses were performed using SPSS version 20.0.

\section{Results}

Of 145 patients, there were 93 males and 52 females $(1.78: 1)$ with a mean age of $61.48 \pm 12.86$ years. 36 patients $(9.4 \%)$ had signet ring cell carcinoma and 109 patients $(90.6 \%)$ had non-signet ring cell carcinoma. Clinical and therapeutic features of patients with SRCC are summarized in Table 1.

Table 1: Clinical, and therapeutic features of patients with gastric signet ring cell carcinoma.

\begin{tabular}{|c|c|c|c|}
\hline \multicolumn{2}{|l|}{ Variables } & \multirow{2}{*}{$\begin{array}{l}\begin{array}{l}\text { No of } \\
\text { patients }\end{array} \\
9\end{array}$} & \multirow{2}{*}{$\begin{array}{l}\% \\
25 \%\end{array}$} \\
\hline Age (mean, & $\geq 60$ years & & \\
\hline $\begin{array}{l}\text { years) } \\
54.25 \text { (29-85) }\end{array}$ & $<60$ years & 27 & $75 \%$ \\
\hline \multirow[t]{2}{*}{ Gender } & Men & 21 & $58.3 \%$ \\
\hline & Women & 15 & $41.7 \%$ \\
\hline \multirow[t]{9}{*}{ Symptoms } & Gastric pain & 34 & $94.9 \%$ \\
\hline & Vomiting & 15 & $41.7 \%$ \\
\hline & Melena & 1 & $2.8 \%$ \\
\hline & Hematemesis & 3 & $8.3 \%$ \\
\hline & Abdominal mass & 1 & $2.8 \%$ \\
\hline & Asthenia & 28 & $77.8 \%$ \\
\hline & Anorexia & 29 & $80.6 \%$ \\
\hline & Weight Loss & 31 & $86.1 \%$ \\
\hline & Dysphagia & 31 & $2.8 \%$ \\
\hline \multirow{4}{*}{$\begin{array}{l}\text { Tumor } \\
\text { location }\end{array}$} & Cardia & 3 & $8.3 \%$ \\
\hline & Gastric fundus & 12 & $33.3 \%$ \\
\hline & Gastric antrum & 19 & $52.8 \%$ \\
\hline & Whole stomach & 2 & $5.6 \%$ \\
\hline \multirow[t]{2}{*}{ Stenosis } & No & 27 & $75 \%$ \\
\hline & Yes & 9 & $25 \%$ \\
\hline \multirow{2}{*}{$\begin{array}{l}\text { Surgical } \\
\text { resection }\end{array}$} & TG & 23 & $63.9 \%$ \\
\hline & PG & 13 & $36.1 \%$ \\
\hline \multirow[t]{2}{*}{ MVR } & No & 28 & $77.8 \%$ \\
\hline & Yes & 8 & $22.2 \%$ \\
\hline \multirow[t]{3}{*}{ LND } & D1 & 4 & $11.1 \%$ \\
\hline & D1.5 & 8 & $22.2 \%$ \\
\hline & D2 & 24 & $66.7 \%$ \\
\hline
\end{tabular}




\begin{tabular}{|l|l|l|l|}
\hline Treatment & Surgery alone & 10 & $27.8 \%$ \\
\cline { 2 - 4 } & NACT+S+CT/RT & 4 & $11.1 \%$ \\
\cline { 2 - 4 } & S+ADJ CT & 8 & $22.2 \%$ \\
\cline { 2 - 4 } & S+ADJ RTCT/RT & 14 & $38.9 \%$ \\
\hline
\end{tabular}

TG: total gastrectomy, PG: partial gastrectomy, MVR: multivisceral resection, LND: Lymph node dissection; S: surgery, NACT: neoadjuvant chemotherapy, ADJ: adjuvant chemotherapy, ADJ RTCT/RT: adjuvant radio-chemotherapy or radiation therapy

The mean age of patients with SRCC was $54.25 \pm 11.49$ years. The most common complaint was abdominal pain (34 patients, $94.9 \%$ ). The tumor was located in the cardia in three cases $(8.3 \%)$, in the gastric fundus in twelve cases $(33.3 \%)$, in the gastric antrum in 19 cases $(52.8 \%)$ and in the whole stomach in 2 cases (30.4\%). Total gastrectomy (TG) was the most common surgical procedure, performed in $63.9 \%$ of cases (23 patients) while $36.1 \%$ of patients had partial gastrectomy (PG). Multivisceral organ resection was necessary in eight patients (22.2\%). We performed a D2 lymph node dissection (LND) in 24 cases $(66.7 \%)$, a D1.5 LND in eight patients $(22.2 \%)$ and four patients $(11.1 \%)$ underwent a D1 lymph node dissection (LND).

Neoadjuvant chemotherapy was administrated in four cases $(11.1 \%)$. Thirty two patients $(88.9 \%)$ underwent primary surgical resection which was followed by adjuvant chemotherapy in eight cases (22.2\%), adjuvant radiation therapy or concomitant radio chemotherapy in 14 cases $(38.9 \%)$ and ten patients $(27.8 \%)$ were treated by exclusive surgical resection (Table 1).

The pathological features of patients with SRCC are listed in table 1 . Complete surgical resection R0 was achieved in 32 patients $(88.9 \%)$ and four patients (11.1\%) had incomplete resection (R1/R2). The mean tumor size was $74.3 \pm 46.53 \mathrm{~mm}$ and $61.1 \%$ of lesions exceeded $50 \mathrm{~mm}$. Perineural and lymphovascular invasion were found in 21 patients (58.3\%). Depth of tumor invasion according to the 8th edition AJCC/ UICC TNM system was pT1 in 2 cases $(5.6 \%)$, pT2 in 5 cases (13.9\%), pT3 in 17 cases $(47.2 \%)$ and pT4in 12 cases $(33.3 \%)$.

The mean number of retrieved lymph node was 22.28 \pm 9.48 (range, 9 - 50) with less than 15 extracted LN in seven cases $(19.4 \%)$. Lymph node metastasis was found in 32 patients $(88.9 \%)$ and the mean number of metastatic lymph node was $11.81 \pm 8.61$ (range, 1-38). LNR was greater than $25 \%$ in $66.7 \%$ of cases. Thirty patients were staged pN2-N3 $(83.3 \%)$ and six patients $(16.7 \%)$ were staged pN0-N1. Advanced stages (stage III and IV) were found in $78.8 \%$ of cases according to the AJCC classification.

Clinicopathologic characteristics were compared between signet ring cell carcinoma (SRC) and non-signet ring cell carcinoma (NSRC) and represented in Table 2.
Table 2: Pathological characteristics of patients with SRCC

\begin{tabular}{|c|c|c|c|}
\hline \multicolumn{2}{|l|}{ Variables } & \multirow{2}{*}{$\begin{array}{l}\begin{array}{l}\text { No of } \\
\text { patients }\end{array} \\
14\end{array}$} & \multirow{2}{*}{$\begin{array}{l}\% \\
38.9 \%\end{array}$} \\
\hline Tumor & $<50 \mathrm{~mm}$ & & \\
\hline $\begin{array}{l}\text { (range, } \\
15 \mathrm{~mm}- \\
60 \mathrm{~mm} \text { ) }\end{array}$ & $\geq 50 \mathrm{~mm}$ & 22 & $61.1 \%$ \\
\hline \multirow[t]{4}{*}{ pT stage } & pT1 & 2 & $5.6 \%$ \\
\hline & pT2 & 5 & $13.9 \%$ \\
\hline & pT3 & 17 & $47.2 \%$ \\
\hline & pT4 & 12 & $33.3 \%$ \\
\hline \multirow[t]{5}{*}{ pN stage } & pNo & 4 & $11.1 \%$ \\
\hline & pN1 & 2 & $5.6 \%$ \\
\hline & pN2 & 7 & $19.4 \%$ \\
\hline & pN3a & 14 & $38.9 \%$ \\
\hline & $\mathrm{pN} 3 \mathrm{~b}$ & 9 & $25 \%$ \\
\hline \multirow[t]{2}{*}{ pM stage } & pM0 & 32 & $88.9 \%$ \\
\hline & pM1 & 4 & $11.1 \%$ \\
\hline \multirow[t]{4}{*}{ AJCC stage } & I & 2 & $5.6 \%$ \\
\hline & II & 6 & $16.7 \%$ \\
\hline & III & 25 & $66.7 \%$ \\
\hline & IV & 4 & $11.1 \%$ \\
\hline \multirow{2}{*}{$\begin{array}{l}\text { NRLN } \\
\text { (mean, } \\
\text { range) } \\
22 \text { (min } \\
\text { 9-max 50) }\end{array}$} & NRLN <15 LN & 7 & $19.4 \%$ \\
\hline & NRLN $\geq 15$ LN & 29 & $80.6 \%$ \\
\hline \multirow{4}{*}{$\begin{array}{l}\text { NMLN } \\
\text { (mean, } \\
\text { range) } \\
11.81 \text { (min } \\
1-\operatorname{max38)}\end{array}$} & LNR0 & 4 & $11.1 \%$ \\
\hline & LNR1 & 2 & $5.6 \%$ \\
\hline & LNR2 & 6 & $16.7 \%$ \\
\hline & LNR3 & 26 & $66.7 \%$ \\
\hline \multirow[t]{2}{*}{ PNI } & No & 15 & $41.7 \%$ \\
\hline & Yes & 21 & $58.3 \%$ \\
\hline
\end{tabular}




\begin{tabular}{|c|c|c|c|}
\hline \multirow[t]{2}{*}{ LVSI } & No & 15 & $41.7 \%$ \\
\hline & Yes & 21 & $58.3 \%$ \\
\hline \multirow[t]{2}{*}{ Resection } & R0 & 32 & $88.9 \%$ \\
\hline & R1/R2 & 4 & $11.1 \%$ \\
\hline \multicolumn{4}{|c|}{$\begin{array}{l}\text { NRLN: number of retrieved lymph node, NMLN: number } \\
\text { of metastatic lymph node, LNR: lymph node ratio, LNR0: } \\
\text { LNR=0; LNR:0\% < LNR } \leq 10 \% \text {; LNR2: } 10 \%<\text { LNR } \leq 25 \% \text {, } \\
\text { LNR3: LNR> } 25 \% \text {, PNI: Perineural evasion; LVSI: lympho- } \\
\text { vascular space invasion. }\end{array}$} \\
\hline
\end{tabular}

Signet ring cell carcinoma presented at a younger age $(p=0.001)$ with no significant difference in gender.

Most of cases of SRCC were located in the middle and lower third of the stomach ( $33.3 \%$ and $52.8 \%$ respectively). Patients with signet ring cell carcinoma were more likely to present with more advanced stage III-IV disease (77.8\% vs $51.4 \%, p=0.005)$.A depth of tumor invasion greater than $\mathrm{T} 2$ was found more frequently in patients with SRCC $(80.6 \%)$ than in those with NSRCC (69.7\%). Advanced $\mathrm{N}$ stages were significantly more prevalent in SRCCs with particularly a higher rate of pN3 $(63.9 \%$ vs $22 \%$, p 0.0001), a higher number of invaded lymph nodes (11.81 vs 6.82, $\mathrm{p}=0.002)$, and a higher rate of patients with a lymph node ratio exceeding $25 \%(63.9 \%$ vs $36.7, \mathrm{p}=0.004)$.

The median follow up was 35.30 months (range 2-139 months). After exclusion of five cases of postoperative death and one patient lost of view, there was no significant difference in the 5 years overall survival between SRCC and NSRCC $(36.7 \%$ vs $45.7 \%$, respectively, $p=0.206)$.
However, patients with SRCC stage pT4 seems to have a worse 5 years OS compared to those with NSRCC without statistically significant difference (0 vs $23.6 \%$ respectively, $\mathrm{p}=0.068$ ).

The univariate analysis of the prognostic factors associated of the 5 years OS of SRCC showed that the tumoral stenosis $(p=0.039)$, hypoprotidemia $(<0.0001)$, the depth of invasion $(\mathrm{p}=0.003)$, perineural invasion (PNI) $(<0.0001)$, lymphovascular space invasion (LVSI) $(<0.0001)$, and UICC stage $(\mathrm{p}=0.007)$ (Figure 1) were the main prognostic factors of overall survival in SRCC (Table 3).

The overall survival was not correlated to the type of

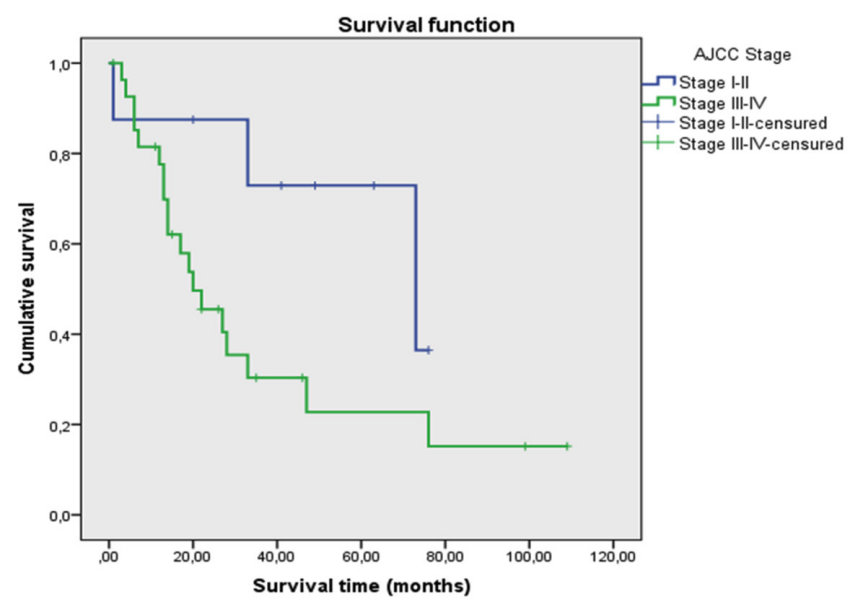

Figure 1: Kaplan-Meier (KM) survival curves of OS according to the AJCC stage. There were significant differences $(p=0.007)$.

Table 3: Comparison of the Clinicopathological Characteristics and survival outcomes of Patients with Signet-Ring Cell Carcinoma (SRC) and non-signet ring cell carcinoma (NSRC)

\begin{tabular}{|c|c|c|c|c|}
\hline \multicolumn{2}{|l|}{ Variables } & SRCC & NSRCC & p \\
\hline \multirow[t]{2}{*}{ Gender } & Male & $21(58.3 \%)$ & $72(66.1 \%)$ & \multirow[t]{2}{*}{0.402} \\
\hline & Female & 15 (41.7\%) & $37(33.9 \%)$ & \\
\hline \multirow[t]{4}{*}{ Tumor location } & Upper third & $3(8.3 \%)$ & $18(16.5 \%)$ & \multirow[t]{4}{*}{0.06} \\
\hline & Middle third & $12(33.3 \%)$ & $33(30.3 \%)$ & \\
\hline & Lower third & $19(52.8 \%)$ & $58(53.2 \%)$ & \\
\hline & Whole & $2(5.6 \%)$ & 0 & \\
\hline \multirow[t]{2}{*}{ Age } & $\leq 65$ years & $31(86.1 \%)$ & $59(54.1 \%)$ & \multirow[t]{2}{*}{0.001} \\
\hline & $>65$ years & $5(13.9 \%)$ & $50(45.9 \%)$ & \\
\hline \multirow[t]{2}{*}{ Tumor size } & $<50 \mathrm{~mm}$ & $14(38.9 \%)$ & $44(40.4 \%)$ & \multirow[t]{2}{*}{0.875} \\
\hline & $\geq 50 \mathrm{~mm}$ & $22(61.1 \%)$ & $65(59.6 \%)$ & \\
\hline \multirow[t]{2}{*}{ pT stage } & pT1-T2 & 7 (19.4\%) & $33(30.3 \%)$ & \multirow[t]{2}{*}{0.207} \\
\hline & pT3-T4 & $29(80.6 \%)$ & $76(69.7 \%)$ & \\
\hline
\end{tabular}




\begin{tabular}{|c|c|c|c|c|}
\hline \multirow[t]{4}{*}{ pN stage } & pNo & $4(11.1 \%)$ & $22(20.2 \%)$ & $<0.0001$ \\
\hline & $\mathrm{pN} 1$ & $2(5.6 \%)$ & $29(26.6 \%)$ & \\
\hline & $\mathrm{pN} 2$ & $7(19.4 \%)$ & $34(31.2 \%)$ & \\
\hline & $\mathrm{pN} 3$ & $23(63.9 \%)$ & $24(22 \%)$ & \\
\hline \multirow[t]{2}{*}{ LNR } & $\leq 25 \%$ & $13(36.1 \%)$ & $69(63.3 \%)$ & \multirow[t]{2}{*}{0.004} \\
\hline & $>25 \%$ & $23(63.9 \%)$ & $40(36.7 \%)$ & \\
\hline NMLN & & $11.81 \pm 8.611$ & $6.82 \pm 7.297$ & 0.002 \\
\hline \multirow[t]{2}{*}{ UICC stage } & Stage I-II & $8(22.2 \%)$ & $53(48.6 \%)$ & \multirow[t]{2}{*}{0.005} \\
\hline & Stage III-IV & $28(77.8 \%)$ & $56(51.4 \%)$ & \\
\hline \multirow[t]{2}{*}{ LVSI } & No & $15(41.7 \%)$ & $58(53.2 \%)$ & \multirow[t]{2}{*}{0.230} \\
\hline & Yes & $21(58.3 \%)$ & $51(46.8 \%)$ & \\
\hline \multirow[t]{2}{*}{ PNI } & No & $15(41.7 \%)$ & $61(56 \%)$ & \multirow[t]{2}{*}{0.136} \\
\hline & Yes & $21(58.3 \%)$ & $48(44 \%)$ & \\
\hline \multirow[t]{2}{*}{ Metastatic recurrence } & No & $16(47.1 \%)$ & $74(70.5 \%)$ & \multirow[t]{2}{*}{0.013} \\
\hline & Yes & $18(52.9 \%)$ & $31(29.5 \%)$ & \\
\hline \multirow[t]{2}{*}{ Peritoneal recurrence } & No & $24(64.7 \%)$ & $95(90.5 \%)$ & \multirow[t]{2}{*}{$<0.0001$} \\
\hline & Yes & $12(35.3 \%)$ & $10(9.5 \%)$ & \\
\hline 5 years OS & & $36.7 \%$ & $45.7 \%$ & 0.206 \\
\hline 5 years PFS & & $38.7 \%$ & $50.9 \%$ & 0.038 \\
\hline
\end{tabular}

gastrectomy and the lymphadenectomy extend.

The 5 years overall survival was higher when complete surgical resection (R0) is achieved, compared to R1/R2 resection $(41 \%$ vs $0 \%$ respectively, $p=0.069)$. The number of retrieved lymph node exceeding 15 seems to enhance the 5 years OS (38.7\% in case of more than 15 retrieved $\mathrm{LN}$ and $21.4 \%$ if the NRLN was less than $15 \mathrm{LN}, \mathrm{p}=0.330$ ). According to $\mathrm{N}$ stage, patients with $\mathrm{pN} 0-\mathrm{N} 1$ stages had better 5 years OS rate compared to patients with pN2-N3 $(62.5 \%$ vs $30 \%, p=0.431)$.

The 5 years progressive free survival (PFS) was significantly decreased in SRCC compared to NSRCC ( $38.7 \%$ vs $50.9 \%$ respectively, $\mathrm{p}=0.038$ ) (Figure 2 ).

From the 145 patients, 49 patients $(33.8 \%)$ presented a metastatic recurrence with significant higher rate of metastasis in SRCC compared to NCRCC (52.9\% vs $29.5 \%$ respectively, $p=0.013$ ). Moreover, we found that the rate of peritoneal recurrence was significantly higher in patients with SRCC compared to those with NSRCC ( $35.3 \%$ vs $9.5 \%$ respectively, $\mathrm{p}<0.0001)$.

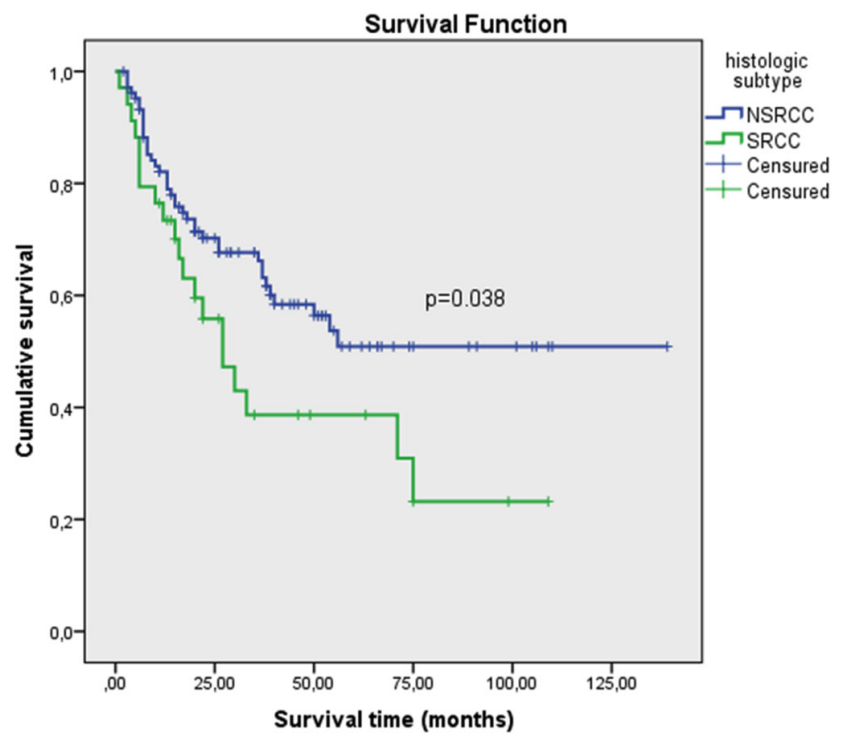

Figure 2: Kaplan-Meier survival curves of PFS by Histological type. There were significant differences betwen SRC and $\operatorname{NSRC}(p=0.038)$.

The 5 years PFS rate of SRCC was $38.7 \%$ and the 10 years PFS rate was $23.2 \%$.Univariate analysis showed that 
tumoral stenosis $(\mathrm{p}=0.042)$, hypoprotidemia $(<0.0001)$, tumor size $(\mathrm{p}=0.049)$, depth of invasion $(\mathrm{p}=0.001)$, PNI $(<0.0001)$, LVSI $(<0.0001)$, UICC stage $(p=0.026)$ (Figure $3)$ and complete surgical resection $(p=0.021)$ were the main prognostic factors of PFS in SRCC (Table 3).

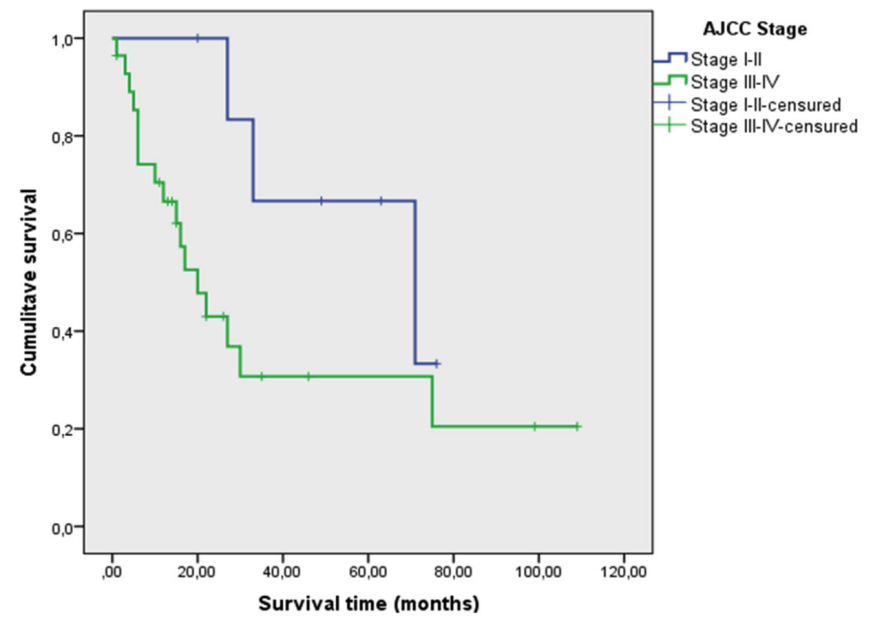

Figure 3: Kaplan-Meier (KM) survival curves of PFS according to AJCC stage. There were significant differences between stage I-II and stage III-IV ( $p=0.026)$.

The PFS was not correlated to the type of gastrectomy and the lymphadenectomy extend. However, the 5 years PFS of patients with more than 15 retrieved lymph nodes seems to be improved compared to those with less than 15 retrieved lymph nodes (41.4\% vs $25.7 \%$ respectively, $\mathrm{p}=0.588$ ). According to $\mathrm{N}$ stage, patients with $\mathrm{pN} 0-\mathrm{N} 1$ stages had a better 5 years PFS rate compared to patients with pN2-N3 (50\% vs 37\%, p=0.514).

\section{Discussion}

Our study suggests that SRCC are frequently characterized by larger tumor size with stenosis, advanced stage, and presence of LNI, PNI and lymph node metastasis as well as a different pattern of spread and recurrence. The study of predictive factors of survival and recurrence suggest that the prognosis of SRCC depends not only on the classic prognostic factors recognized in all gastric adenocarcinoma, but also on the stenotic nature of the lesions and the nutritional status of patients. The type of gastrectomy does not affect longterm results if resection margin is adequate.

SRCC have clinical features that distinguish them from other histological types and the prognosis of these cancers remains controversial because of their specific behavior that may suggest an adjustment of therapeutic modalities.

Many studies reported that gastric SRCC is commonly more frequent in young patients and females[6, 7] and seems to be related to hormonal status.[8] Similar results were found in our study with a significantly higher rate of patients under 65 years of age in SRCC compared to NSRCC $(86.5 \%$ vs $54.1 \%$; $p=0.001)$. However, we observed that the male to female ratio was similar for the two groups which is line with the results of $\mathrm{Li}$ and al who compared 4097 cases of NSRCC to 662 cases of SRCC without significant difference in gender (the rate of male was $67.3 \%$ vs $68 \%$ respectively and the rate of female was $32.7 \%$ vs $31.1 \%$ respectively, $p=0.418)$. [9] Nie et al reported in their recent meta-analysis of 19 studies including 35947 cases, that SRCC tends to be located in the middle and lower third of the stomach $\left(\mathrm{OR}=0.62,95 \% \mathrm{CI}=0.47-0.81, \mathrm{P}<0.001 ; \mathrm{I}^{2}=82.0 \%, \mathrm{P}<0.001\right)$ compared to non-signet ring cell carcinoma (NSRCC). [10] We also reported that most of cases of SRCC were located in the lower third (52.8\%) and the middle third $(33.3 \%)$ of the stomach. We found that patients with SRCC were more likely to present at later stages, with a greater proportion of patients presenting at AJCC stage III $(66.7 \%)$, with deeper parietal invasion and a higher rate of lymph node metastasis which is in line with the results of Taghavi and Piessen.[7, 11]

Lymphovascular and perineural invasion are more commonly seen in gastric SRCC. In fact, Kwon et al. reported that the rate of PNI and LVSI were respectively $7.8 \%$ and $11.8 \%$ in early SRCC and $56.1 \%$ and $64.9 \%$ in advanced SRCC.[12] In our study, $58.3 \%$ of patients had PNI and LVSI compared to $44 \%$ and $46.8 \%$ respectively in NSRCC. We also found that patients with SRCC were more likely to present with larger tumor size, since $61.1 \%$ of tumors measured more than $50 \mathrm{~mm}$. Chen and al reported that according to Lauren classification, diffuse and mixed tumors were significantly associated with larger tumors exceeding 80mm.[13]

Although most authors agree on the poor prognosis of diffuse type of gastric carcinoma according to the Lauren classification, the prognosis of SRCCs as a particular entity remains debated and varies according to stage at diagnosis. Indeed, in early gastric cancer, some studies showed that early SRCC has a better prognosis than NSRCC.[12, 14, 15] Other authors demonstrated no difference in survival between the two histological groups in the early stages.[16, 17] However, in advanced gastric cancer, Li et al[9] and Piessen et al.[11]found that the 5-years survival rate of SRCC was significantly poorer than that of NSRCC.

In our study the 5-year overall survival rate was 35.7\%. Regarding tumor stage, the 5 years overall survival was shorter in stage III and IV compared to stage I and II ( $22.8 \%$ vs $72.9 \%, p=0.007)$. Similar rates were reported by Liu et al with a 5 years OS of $93.9 \%$ in stage I, $58.7 \%$ in stage II and $25.3 \%$ in stage III and IV.[18] Few studies investigated the recurrence and progressive free survival in SRCC according the common prognostic factors. In our study, the rate of recurrence was $55.6 \%$ and the 5 years progression-free survival rate was $38.7 \%$. Lower rates of relapses were reported by Voron et al (45.75\%) and Zhang et al (45\%).[19, 20] Moreover, in our study we reported a higher rate of distant metastasis in SRCC compared to NSRCC (52.9\% vs $29.5 \%$, p $=0.013)$ which is in line with the results of Postlewait and al who compared the outcomes of 312 patients with SRCC to 456 patients with NSRCC and suggested a significant difference in term of distant relapses (28.2\% vs 20.2\%, respectively, $p=0.013)$.[21] Piessen and al[11] analyzed the trend of recurrence after a complete resection between 23 cases of SRCC and 42 cases of NSRCC and found that peritoneal relapses occurred more frequently in patients with SRCC (52.2\% vs $21.4 \%, \mathrm{p}=0.001)$ which is similar to our finding.

Lymph node metastasis and depth of parietal invasion 
are the most important prognostic factors of gastric carcinoma.[22-25] In the majority of studies analyzing the survival outcomes of SRCC, the depth of invasion, as well as LN metastasis, are the independent prognostic factors of recurrence and survival.[18-20] In our study, pT stage was also significantly correlated to survival outcomes and the 5-years OS rate and PFS rate were lower in patients with pN2-N3 compared to those with pN0-N1 (30\% and 37\% respectively vs $62.5 \%$ and $50 \%$ ). However, the difference was not significant, and this could be explained by the particularly high rate of lymph node involvement in our series (only 4 patients were staged pN0) but also the reduced number of patients.

Although the prognostic value of tumor size remains debatable, it has been reported to be an independent prognostic factor by many authors.[26, 27]In our study, a tumor size more than $50 \mathrm{~mm}$ was significantly associated with a decline in overall survival as well as progressionfree survival which is consistent with the results of Liu et al who reported a decrease of the 5-years OS in tumors larger than $50 \mathrm{~mm}(16.7 \%$ vs $48.8 \%$ p<0.001).[18]

Several studies investigated the pejorative prognostic value of lymphovascular space invasion and perineural invasion in gastric cancer.[28-32] Moreover, this pejorative prognostic effect of PNI and LVI was also found in SRCC. In fact, in the study by Liu et al[18], the 5 -years OS was significantly decreased in the presence of LVI $(49.4 \%$ versus $15.1 \%, p<0.001)$ and PNI $(46.3 \%$ versus $21.4 \%, p<0.001)$ which is in line with our finding. In a study comparing 218 patients with SRCC to 1221 patients with NSRCC, Zhang et al reported that curative resection with negative margins represents an independent predictor of overall survival in the subgroup of patients with SRCC ( $\mathrm{HR}=2.878,95 \% \mathrm{CI}=1.865-4.440$, $\mathrm{p}<0.001)$.[20] In our study, both of OS and PFS were significantly improved by complete surgical resection. However, the extend of gastrectomy was not correlated to survival outcomes, in case of complete resection, and total gastrectomy resulted in a worse 5 years OS and PFS. These findings are supported by many other authors. In the retrospective study of Voron et al, including a total of 899 SRCC treated by total gastrectomy in 576 cases $(60.7 \%)$ and partial gastrectomy in 353 cases $(39.3 \%)$, complete surgical resection was achieved in $79.8 \%$ of cases and the overall survival was not correlated to the type of gastrectomy on multivariate analysis ( $\mathrm{HR}=0.900$, 95\% CI= 0.718-1.128, p<0.359).[19] Despite a higher risk of lymph node involvement in SRCC, there is no specific recommendation about the extent of lymphadenectomy for advanced SRCC. As for other histological types, a modified D2 lymphadenectomy retrieving at least 15 lymph nodes is recommended.[33] Thus, we found a gain in terms of OS and PFS if the number of removed lymph nodes was greater than $15 \mathrm{LN}$, even if the difference was not statistically significant $(38.7 \%$ and $41.7 \%$ respectively if the NRLN was greater than $15 \mathrm{LN}$, $21.4 \%$ and $25.7 \%$ respectively if the NRLN was less than $15 \mathrm{LN})$.

Several studies showed that malnutrition, especially hypoprotidemia and weight loss, were a prognostic factor for survival and recurrence.[34, 35] However, in studies dedicated to gastric SRCC, the long-term prognostic value of hypoprotidemia has rarely been evaluated. Voron et al reported that cancer related malnutrition was significantly associated to a worse OS in SRCC as well as NSRCC.[19] However, in the present report, the 5 years OS was significantly reduced with hypoprotidemia $(52.5 \%$ vs $0 \%, \mathrm{p}<0.0001)$ and it was the same for the 5 years PFS (55.5\% vs $0 \%, \mathrm{p}=0.001)$. Weight loss of more than $10 \%$ of the usual weight was also associated to lower rate of 5 years OS $(23.7 \%$ vs $45.5 \%$ if the weight loss was less than $10 \%$ ) and a lower rate of 5 years PFS $(30.3 \%$ vs $54.5 \%$ if the weight loss was less than $10 \%$ ). We also found that patients presenting with tumoral stenosis had a worse OS and PFS which is consistent with the report of Chen et al.[13]

Despite the limited number of patients enrolled in this retrospective and single institution study, we suggest that SRCC remain an aggressive clinical subtype of gastric cancer characterized with advanced stage and a worse survival outcome compared to NSRCC.

\section{Conclusion}

The incidence of SRCC is increasing in recent years and their prognosis seems to be equivalent to that of gastric adenocarcinoma or better in the early stages. However, it would be more reserved in the advanced stages. Although this study helped to describe clinical and histological features and survival outcomes, it has some limitations due to small sample size. Clinical studies with larger patient groups and comparative study with NSRCC could be helpful to understand its clinicopathological behavior.

\section{Acknowledgements \\ None}

\section{Contributors}

IZ, HM, IBS, MAA, TBD, RC, KR conceptualized and designed the study, acquired, and analyzed data, interpreted the study results, drafted the manuscript, and critically revised the final version of the manuscript.

\section{Funding}

The authors received no financial support for the research, authorship, and/or publication of this article.

\section{Competing interests}

No benefits in any form have been received or will be received from a commercial party related directly or indirectly to the subject of this article.

\section{Availability of data and materials}

Further information is available from the corresponding author on reasonable request.

\section{Ethics approval}

The ethics review board approved this study and did not require informed consent from study participants since this was a strictly registry-based study.

\section{Provenance and peer review}

Not commissioned; externally peer reviewed.

\section{Open access}

This is an Open Access article distributed in accordance 
with the Creative Commons Attribution NonCommercial (CC BY-NC 4.0) license, which permits others to distribute, remix, adapt, build upon this work noncommercially, and license their derivative works on different terms, provided

the original work is properly cited and the use is non-commercial. See: http://creativecommons.org/ licenses/by-nc/4.0/

\section{References}

[1] Hass HG, Smith U, Jäger C, Schaeffer M, Wellhaeusser U, Hehr T, et al. Signet ring cell carcinoma of the stomach is significantly associated with poor prognosis and diffuse gastric cancer (Lauren's): singlecenter experience of 160 cases. Oncology Research and Treatment. 2011;34:682-6.

[2] Chu PG, Weiss LM. Immunohistochemical characterization of signet-ring cell carcinomas of the stomach, breast, and colon. American journal of clinical pathology. 2004;121:884-92.

[3] Lauren P. The two histological main types of gastric carcinoma: diffuse and so-called intestinal-type carcinoma: an attempt at a histoclinical classification. Acta Pathologica Microbiologica Scandinavica. 1965;64:31-49.

[4] Nakamura T, Nakano G. Histopathological classification and malignant change in gastric polyps. Journal of clinical pathology. 1985;38:754-64.

[5] Lee HH, Song KY, Park CH, Jeon HM. Undifferentiated-type gastric adenocarcinoma: prognostic impact of three histological types. World journal of surgical oncology. 2012;10:254.

[6] Ćerban D, Brănescu C, Ćavlovschi C, Tiucă F, Tudor C, Kraft A, et al. Particularităli clinico-morfologice într-un caz de carcinom gastric incipient (tipul de carcinom în inel cu pecete). Chirurgia. 2011;106:3837.

[7] Taghavi S, Jayarajan SN, Davey A, Willis AI. Prognostic significance of signet ring gastric cancer. Journal of clinical oncology. 2012;30:3493. [8] Matsuyama S, Ohkura Y, Eguchi H, Kobayashi Y, Akagi K, Uchida $K$, et al. Estrogen receptor $\beta$ is expressed in human stomach adenocarcinoma. Journal of cancer research and clinical oncology. 2002;128:319-24.

[9] Li C, Kim S, Lai JF, Hyung WJ, Choi WH, Choi SH, et al. Advanced gastric carcinoma with signet ring cell histology. Oncology. 2007;72:648.

[10] Nie R-C, Yuan S-Q, Li Y-F, Chen Y-M, Chen X-J, Zhu B-Y, et al. Clinicopathological characteristics and prognostic value of signet ring cells in gastric carcinoma: A meta-analysis. Journal of Cancer. 2017;8:3396.

[11] Piessen G, Messager M, Leteurtre E, Jean-Pierre T, Mariette C. Signet ring cell histology is an independent predictor of poor prognosis in gastric adenocarcinoma regardless of tumoral clinical presentation. Annals of surgery. 2009;250:878-87.

[12] Kwon K-J, Shim K-N, Song E-M, Choi J-Y, Kim S-E, Jung H-K, et al. Clinicopathological characteristics and prognosis of signet ring cell carcinoma of the stomach. Gastric Cancer. 2014;17:43-53.

[13] Chen Y-C, Fang W-L, Wang R-F, Liu C-A, Yang M-H, Lo S-S, et al. Clinicopathological variation of Lauren classification in gastric cancer. Pathology \& Oncology Research. 2016;22:197-202.

[14] Kunisaki C, Shimada H, Nomura M, Matsuda G, Otsuka Y, Akiyama $\mathrm{H}$. Therapeutic strategy for signet ring cell carcinoma of the stomach. British journal of surgery. 2004;91:1319-24.

[15]Jiang CG, Wang ZN, Sun Z, Liu FN, Yu M, Xu HM. Clinicopathologic characteristics and prognosis of signet ring cell carcinoma of the stomach: Results from a chinese mono-institutional study. Journal of surgical oncology. 2011;103:700-3.

[16] Gronnier C, Messager M, Robb WB, Thiebot T, Louis D, Luc G, et al. Is the negative prognostic impact of signet ring cell histology maintained in early gastric adenocarcinoma? Surgery. 2013;154:1093-9. [17] Kim DY, Park YK, Joo JK, Ryu SY, Kim YJ, Kim SK, et al. Clinicopathological characteristics of signet ring cell carcinoma of the stomach. ANZ journal of surgery. 2004;74:1060-4.

[18] Liu X, Cai H, Sheng W, Yu L, Long Z, Shi Y, et al. Clinicopathological characteristics and survival outcomes of primary signet ring cell carcinoma in the stomach: retrospective analysis of single center database. PLoS One. 2015;10:e0144420.

[19] Voron T, Messager M, Duhamel A, Lefevre J, Mabrut J-Y, Goere $\mathrm{D}$, et al. Is signet-ring cell carcinoma a specific entity among gastric cancers? Gastric Cancer. 2016;19:1027-40.

[20] Zhang M, Zhu G, Zhang H, Gao H, Xue Y. Clinicopathologic features of gastric carcinoma with signet ring cell histology. Journal of Gastrointestinal Surgery. 2010;14:601-6.

[21] Postlewait LM, Squires MH, Kooby DA, Poultsides GA, Weber $\mathrm{SM}$, Bloomston $\mathrm{M}$, et al. The prognostic value of signet-ring cell histology in resected gastric adenocarcinoma. Annals of surgical oncology. 2015;22:832-9.

[22] Song KY, Park YG, Jeon HM, Park CH. A nomogram for predicting individual survival of patients with gastric cancer who underwent radical surgery with extended lymph node dissection. Gastric Cancer. 2014;17:287-93.

[23] Han D-S, Suh Y-S, Kong S-H, Lee H-J, Choi Y, Aikou S, et al. Nomogram predicting long-term survival after $\mathrm{d} 2$ gastrectomy for gastric cancer. J Clin Oncol. 2012;30:3834-40.

[24] Kim DH, Kim SM, Hyun JK, Choi MG, Noh JH, Sohn TS, et al. Changes in postoperative recurrence and prognostic risk factors for patients with gastric cancer who underwent curative gastric resection during different time periods. Annals of surgical oncology. 2013;20:2317-27.

[25] Kim J-P, Kim Y-W, Yang H-K, Noh D-Y. Significant prognostic factors by multivariate analysis of 3926 gastric cancer patients. World journal of surgery. 1994;18:872-7.

[26] Wang X, Wan F, Pan J, Yu GZ, Chen Y, Wang JJ. Tumor size: A non-neglectable independent prognostic factor for gastric cancer. Journal of surgical oncology. 2008;97:236-40.

[27] Saito H, Osaki T, Murakami D, Sakamoto T, Kanaji S, Oro S, et al. Macroscopic tumor size as a simple prognostic indicator in patients with gastric cancer. The American journal of surgery. 2006;192:296-300. [28] Xue L, Chen X-L, Lin P-P, Xu Y-W, Zhang W-H, Liu K, et al. Impact of capillary invasion on the prognosis of gastric adenocarcinoma patients: A retrospective cohort study. Oncotarget. 2016;7:31215.

[29] Del Casar JM, Corte MD, Álvarez A, García I, Bongera M, González LO, et al. Lymphatic and/or blood vessel invasion in gastric cancer: relationship with clinicopathological parameters, biological factors and prognostic significance. Journal of cancer research and clinical oncology. 2008;134:153.

[30] Selcukbiricik F, Tural D, Buyukunal E, Serdengecti S. Perineural invasion independent prognostic factors in patients with gastric cancer undergoing curative resection. Asian Pacific journal of cancer prevention : APJCP. 2012;13:3149-52.

[31] Liebig C, Ayala G, Wilks JA, Berger DH, Albo D. Perineural invasion in cancer: a review of the literature. Cancer: Interdisciplinary International Journal of the American Cancer Society. 2009;115:337991.

[32] Deng J, You Q, Gao Y, Yu Q, Zhao P, Zheng Y, et al. Prognostic value of perineural invasion in gastric cancer: a systematic review and meta-analysis. PloS one. 2014;9:e88907.

[33] Pernot S, Voron T, Perkins G, Lagorce-Pages C, Berger A, Taieb J. Signet-ring cell carcinoma of the stomach: Impact on prognosis and specific therapeutic challenge. World Journal of Gastroenterology: WJG. 2015;21:11428.

[34] Zheng H-L, Lu J, Li P, Xie J-W, Wang J-b, Lin J-X, et al. Effects of preoperative malnutrition on short-and long-term outcomes of patients with gastric cancer: can we do better? Annals of surgical oncology. 2017;24:3376-85.

[35] Crumley AB, Stuart RC, McKernan M, McMillan DC. Is hypoalbuminemia an independent prognostic factor in patients with gastric cancer? World journal of surgery. 2010;34:2393-8. 